\title{
La evolución de la política exterior China ${ }^{1}$
}

\section{The Evolution of China's Foreign Policy}

\author{
Mario Esteban Rodríguez ${ }^{2}$ \\ Universidad Autónoma de Madrid y Real Instituto Elcano
}

Recibido: 04-02-16

Aprobado: 22-02-16

\section{Resumen}

Este artículo sintetiza y analiza los principales cambios experimentados por la política exterior de la República Popular China desde su fundación en 1949 hasta la actualidad. Para explicar esas transformaciones se recurre fundamentalmente a tres variables (la política interna de China, las características del sistema internacional y el contexto de seguridad), que las autoridades chinas han interpretado influidas por tres componentes ideacionales: el comunismo, el nacionalismo y el pragmatismo. A modo de conclusión se subraya que, a pesar de sus vaivenes, la política exterior de Pekín ha mantenido tres objetivos fundamentales en las últimas siete décadas: modernización, reconocimiento internacional como gran potencia y reunificación nacional.

Palabras-clave: política exterior china, relaciones internacionales, acción exterior.

\begin{abstract}
This article summarizes and analyzes the key changes in the foreign policy of the People's Republic of China since its founding in 1949 until nowadays. To

\footnotetext{
${ }^{1}$ Este trabajo forma parte de una investigación realizada gracias al apoyo del Ministerio de Economía y Competitividad (FFI2011-25897). Se publicó una versión preliminar del mismo en Esteban, Mario (2015). "China y su lugar en el mundo", Revista de Occidente 414, pp. 37-48.

2 (mario.esteban@uam.es) Doctor en Ciencias Políticas y Máster en Política Asiática. Es Profesor Titular en el Centro de Estudios de Asia Oriental de la Universidad Autónoma de Madrid e Investigador Principal (Asia-Pacífico) en el Real Instituto Elcano. Ha realizado múltiples estancias de investigación en China y Taiwán. Sus intereses de investigación se centran en las relaciones internacionales de Asia Oriental, las relaciones UE-Asia Oriental, y la política doméstica y exterior de China. Sobre estos temas ha escrito varios libros y numerosos artículos académicos, publicados en revistas como The China Quarterly, Journal of Current Chinese Affairs, African and Asian Studies, and The European Journal of East Asian Studies.
} 
explain these transformations we mainly resort to three variables (the domestic politics of China, the characteristics of the international system, and the security context), that were interpreted by the Chinese authorities influenced by three ideational components: communism, nationalism, and pragmatism. In conclusion, despite its ups and downs, Beijing's foreign policy has kept the same three main goals in the last seven decades: modernization, international recognition as a great power, and national reunification.

Key-words: Chinese foreign policy, international relations, external action.

\section{Introducción}

En los últimos 35 años China ha experimentado una profundísima transformación. El gigante asiático ha cambiado la economía planificada por el mercado y ha pasado de ser un país rural y aislado a convertirse en el principal exportador y el mayor mercado turístico del mundo. Este proceso ha sido de tal magnitud que Eugenio Bregolat, tres veces embajador de España en China, lo ha calificado como la "Segunda Revolución China" (Bregolat 2007).

Según datos del Banco Mundial, la economía China ha crecido a un ritmo vertiginoso durante este periodo, en torno a un 10 por ciento anual, pasando de 1 billón de dólares en 1990 a 17,5 billones en 2014. Esto se ha traducido en un incremento sustancial del peso de China en la economía global, del 4 por ciento en 1990 al 16,5 por ciento en 2014, lo que la convierte en la mayor economía del mundo por paridad de poder adquisitivo.

Un motor fundamental de estos cambios ha sido la apertura de China al exterior, mediante un modelo de desarrollo basado en su inserción en cadenas globales de valor, lo que hizo a este país muy dependiente del contexto internacional. Sin embargo, gracias a su éxito y a las enormes dimensiones del gigante asiático, esta relación de dependencia se ha convertido en interdependencia. A nadie se le escapa que lo que sucede hoy día en China tiene un enorme impacto en los demás países. Basta con recordar que China es el mayor emisor de gases de efecto invernadero o cómo las fluctuaciones en la bolsa china han afectado en los últimos meses a los demás mercados de valores.

En otras palabras, la amplia mutación interna de China se plasma en un impacto ascendente dentro de la comunidad internacional. Esto exige a Pekín modificar su estrategia de acción exterior, su forma de relacionarse con el mundo para defender mejor sus intereses en un entorno rápidamente cambiante; $\mathrm{y}$, a nosotros, prestar atención a la evolución de dicha estrategia, que será clave para entender el papel de China en los asuntos internacionales. Ese es el objeto de estudio de este trabajo, que analiza la evolución de la política exterior de la República Popular China desde su fundación hasta la actualidad. 
Se parte de la premisa de que la política exterior china ha venido condicionada fundamentalmente por la forma en que las autoridades han interpretado en cada momento la situación política interna, las características del sistema internacional y el contexto de seguridad, estando condicionada dicha interpretación por tres ideologías, comunismo, nacionalismo y pragmatismo, cuya influencia ha ido variando a lo largo de los años. La interacción dinámica entre estos factores permite distinguir seis periodos dentro de la política exterior de la República Popular China: la alianza sino-soviética en los años cincuenta, la oposición a las dos superpotencias en la década de los sesenta, el acercamiento a Estados Unidos en los años setenta, la política de puertas abiertas durante la década siguiente, el perfil bajo adoptado tras la supresión de la revuelta de Tiananmen, que ha estado vigente durante unos veinte años, y la aparición de una política exterior más asertiva en los últimos años.

El comunismo y el nacionalismo fueron especialmente influyentes en los años 50 y 60, cuando el régimen maoísta aplicó una política exterior confrontacional para consolidarse en el poder. El deterioro que produjo en el contexto de seguridad de China esa política confrontacional acabó 1levando, en los años 70, a un acercamiento hacia Estados Unidos. Este giro marcará el inicio del protagonismo del pragmatismo como elemento ideacional central a la hora de configurar la política exterior china, cuyo peso se acentuará con la llegada al poder de Deng Xiaoping y su programa reformista. Esta política exterior pragmática se irá adaptando a los cambios del sistema internacional, que en ocasiones perjudicarán a China, como la aparición del momento unipolar tras el fin de la Guerra Fría, y en otras la beneficiarán, como la actual transición hacia un mundo más multipolar.

A pesar de esos vaivenes, la política exterior de Pekín ha mantenido tres objetivos fundamentales durante estas más de seis décadas, modernización, reconocimiento internacional como gran potencia y reunificación nacional, en los que han logrado avances sustanciales.

\section{La alianza sino-soviética}

Toda vez que la victoria en la guerra civil contra el Kuomintang parecía segura, en la segunda mitad de 1948 y los primeros meses de 1949 se celebraron varias reuniones de los máximos órganos de poder del Partido Comunista Chino orientadas a marcar las que serían las principales líneas políticas del nuevo régimen. Esto incluía las bases de su política exterior y de seguridad, cuyo principal pilar fue una estrecha relación con la Unión Soviética que se sintetizó en la política de "ponerse de un lado" (Mao 1949a, 1949b), puesta rápidamente en práctica tras la fundación de la República Popular China con la firma del 
Tratado chino-soviético de amistad, alianza y ayuda mutua en febrero de 1950.

Aunque las afinidades ideológicas entre los comunistas soviéticos y los chinos facilitaron esta alianza, que se reforzó en la primera mitad de los años 50, éstas distan mucho de ser el único factor explicativo ${ }^{3}$. En múltiples ocasiones antes de la fundación de la República Popular China, Stalin se había caracterizado por menospreciar al Partido Comunista Chino, intentar imponerle decisiones que iban en contra del criterio de Mao, y utilizarlo como moneda de cambio frente a Estados Unidos y el Kuomintang para preservar sus propios intereses. De ahí que Mao desconfiase de Moscú (Schram: 15-18).

Sin embargo, había múltiples factores favoreciendo que se fraguase esta alianza. Al tomar el poder, los comunistas chinos eran conscientes de la larga lista de desafíos que debían afrontar en la arena diplomática: lograr el reconocimiento de la comunidad internacional para el nuevo régimen, obtener la ayuda exterior imprescindible para reconstruir y modernizar el país, y avanzar en el proceso de unificación territorial de China. Dado el contexto de rivalidad entre el bloque capitalista y el bloque comunista, y el apoyo que Washington brindaba al Kuomintang, parecía que en realidad sólo había una opción viable para un régimen que ni siquiera tenía visos de ser reconocido diplomáticamente por Estados Unidos. Además, Moscú podía ser un formidable aliado, dado que ofrecía un modelo exitoso de rápida industrialización para una sociedad eminentemente agraria, era potencia nuclear, ocupaba uno de los cinco asientos permanentes del Consejo de Seguridad de Naciones Unidas y había emergido como uno de los dos polos que dividían a la comunidad internacional en la segunda posguerra mundial (Westad 1998, Zhang 2011).

Esto no implica que las autoridades comunistas chinas adoptasen una política exterior meramente reactiva a las iniciativas diplomáticas de las dos superpotencias. El nacionalismo marcadamente anti-imperialista que les imbuía, a ellos y a gran parte de la sociedad civil china, les llevaba a querer terminar con cualquier vestigio de las relaciones de subordinación que durante algo más de un siglo habían impuesto sobre China las potencias imperiales (Hunt 1996; Teiwes 1997). Los comunistas chinos querían enfatizar que el nuevo régimen también marcaba una nueva etapa en las relaciones internacionales de China, que volvía a ser un país independiente y autónomo, con lo que se ponía fin al llamado "siglo de humillación"4. Esto

${ }^{3}$ Chen $(2001)$ y Lüthi $(2008,2010)$ son dos de los autores más destacados que comparativamente confieren un mayor peso a las afinidades ideológicas entre Pekín y Moscú, vis-à-vis el nacionalismo o a la realpolitik, para explicar el estrechamiento de los lazos entre la República Popular China y la Unión Soviética.

${ }^{4}$ El siglo de humillación hace referencia al periodo que va desde el inicio de la Primera Guerra del Opio, en 1839, hasta 1945 o 1949, según sigamos la periodización oficial marcada por el Kuomintang o por el Partido Comunista Chino. Este periodo se caracteriza por las múltiples violaciones de la soberanía de China que cometieron diferentes potencias extranjeras, en la segunda mitad del siglo XIX especialmente Gran Bretaña y en la primera mitad del XX Japón (Scott 2008). 
favorecía un distanciamiento claro y visible de las potencias tradicionales, especialmente al estar Mao convencido de que éstas no estaban preparadas para tratar a Pekín como a un igual (Mao 1949a).

Este alejamiento de Estados Unidos, y por ende del bloque capitalista, se consolidó rápidamente debido a la Guerra de Corea, que tuvo una enorme repercusión sobre la política exterior de Pekín. Las autoridades chinas no entraron en ese conflicto como meros peones de Moscú, sino impulsados por una triple motivación (Chen 1994). Desde una perspectiva de seguridad, querían evitar el establecimiento en su frontera de un régimen pro-estadounidense, que interpretaban como una potencial amenaza constante para su supervivencia. Asimismo, entendían que la nueva China debía ser capaz de apoyar a gobiernos políticamente afines, especialmente en su periferia, si quería ser considerada internacionalmente como un actor político relevante. Además, consideraban que este esfuerzo bélico también les ofrecía una enorme oportunidad propagandística dentro de China, lo que facilitaría la movilización masiva de la población para impulsar las transformaciones institucionales revolucionarias que querían acometer.

La Guerra de Corea distanció todavía más a Pekín de Washington y reforzó la política exterior china de ponerse del lado soviético en un mundo marcadamente bipolar. Durante la década de los 50 esta estrecha colaboración con Moscú aceleró el proceso de industrialización de China, aumentó su visibilidad como un actor significativo dentro de la comunidad internacional, y facilitó parte del proceso de reunificación nacional en que estaba embarcada.

\section{Oposición a la hegemonía de las dos superpotencias}

Detrás de una apariencia de gran solidez, desde su propio origen la alianza sino-soviética estuvo salpicada de múltiples desavenencias ideológicas y estratégicas $^{5}$, que se fueron agudizando en la segunda mitad de los años cincuenta (Gittings 1969, Li 2012). Ello obligó a China, durante toda la década de los 60 , a luchar por hacerse hueco en una escena internacional dominada por dos superpotencias que le eran hostiles. En ese proceso, el deterioro de las relaciones con Moscú acabó siendo tan profundo que, a finales de los años 60, Pekín identificaba a la Unión Soviética como la principal amenaza para su seguridad.

A medida que el primer plan quinquenal (1953-1957) se iba implementando en China, aumentaba la preocupación de Mao por la centralización, burocratización y jerarquización que exigía la economía planificada, pues temía que estos procesos condujesen a la consolidación de una clase burocrática privilegiada, lo que podría desembocar en protestas como las acaecidas en

${ }^{5}$ El propio Khrushchev definió los términos del Tratado chino-soviético de amistad, alianza y ayuda mutua como "un insulto al pueblo chino" (Khrushchev 1970: 463).

Araucaria. Revista Iberoamericana de Filosofía, Política y Humanidades, año 18, no 35. Primer semestre de 2016. Pp. 301-318. ISSN 1575-6823 e-ISSN 2340-2199 doi: 10.12795/araucaria.2016.i35.15 
Hungría y en Polonia en 1956. Estos temores se acentuaron tras la Campaña de las 100 Flores (1956-1957), en la que numerosos intelectuales chinos manifestaron su disconformidad con las políticas del partido. La respuesta de Mao fue buscar un modelo de desarrollo económico alternativo al capitalista y al soviético, que, dadas las condiciones materiales de China, debía fundamentarse en la movilización intensiva de la población. Esto cristalizó en el lanzamiento del Gran Salto Adelante en 1958.

La Guerra de Corea había confirmado a Mao que una situación de crisis internacional podía favorecer la movilización de la población en apoyo de las prioridades políticas marcadas por el partido (Chen 1994: 223). De ahí que Mao no dudase en repetir estrategia tras lanzar el Gran Salto Adelante y provocase una segunda crisis en el estrecho de Taiwán en verano de 1958, bombardeando varias islas controladas por el Kuomintang (Christensen 1996: 194-241). Esta estrategia de agitación internacional contrastaba con la política de coexistencia pacífica defendida por la Unión Soviética, que, en consecuencia, no respaldó a Pekín en esta crisis.

Mao pudo comprobar así que, como él ya se temía, Moscú no estaba dispuesto a apoyarle militarmente, ni siquiera en un asunto tan relevante para Pekín como completar su proceso de unificación nacional, si esto implicaba riesgo de conflicto con Estados Unidos. Es más, para mayor irritación de los líderes chinos, Khrushchev se mostraba intransigente a discutir asuntos como el estatus de Mongolia y la delimitación de las fronteras entre los dos países, pero sí se atrevió, durante una visita a China en 1959, a solicitarles el establecimiento de estaciones de radio en territorio chino y que la marina soviética pudiese contar con apoyo logístico en este país (Khrushchev 1970: 466-474). Los comunistas chinos, fuertemente nacionalistas, eran muy sensibles ante cualquier injerencia de una potencia extranjera en su territorio y hacían de la unificación nacional una de sus principales prioridades, de ahí que estas desavenencias con la Unión Soviética fuesen particularmente significativas para ellos. Además, la intensificación de las diferencias ideológicas entre los dos regímenes se acentuaba precisamente en un momento en que Khrushchev intentaba aumentar la influencia de Moscú sobre la política exterior y de defensa chinas (Mao 1959).

Estas discrepancias entre los dos gigantes comunistas se trasladaron en los años siguientes a una disputa por el liderazgo del movimiento comunista internacional (Lüthi 2008). Desde Pekín se subrayaba la validez de utilizar el mundo rural como base para tomar el poder por la vía armada, incluso si esto supusiese un conflicto directo con Estados Unidos. Esta fragmentación del bloque soviético se hizo particularmente visible a partir de la gran conferencia que en 1960 reunió en Moscú a más de 80 partidos comunistas de todo el planeta, a medida que algunos partidos comunistas asumieron los postulados 
chinos, especialmente en países en vías de desarrollo, y otros se dividieron en facciones pro-chinas y pro-soviéticas.

Las discrepancias ideológicas y la creciente competencia diplomática entre Pekín y Moscú no sólo provocaron la retirada de la ayuda soviética, también dieron lugar a una preocupante sensación de amenaza en China ante una posible intervención militar soviética en su territorio, ya fuese para destruir sus instalaciones nucleares y evitar que China desarrollase armamento nuclear o para resolver las múltiples disputas territoriales que mantenían (Robinson 1972). Las negociaciones celebradas en 1964 entre los dos países para consensuar sus límites fronterizos no fructificaron y el cambio de liderazgo en la Unión Soviética tampoco mejoró el clima con Pekín. Las tensiones y escaramuzas fronterizas entre ambos países fueron escalando hasta que en marzo de 1969 dos incidente en la isla Chen-pao o Damansky en el río Ussuri se saldaron con unas 1000 bajas en total, la mayoría chinas. Con los precedentes en 1968 de la invasión soviética de Checoslovaquia y la declaración de la doctrina Breznhev, que justificaba la intervención militar de la Unión Soviética en estados comunistas, en Pekín se entendía que un ataque soviético contra China era un escenario bastante plausible. Esta amenaza tangible para su seguridad fue el factor esencial que propició la búsqueda por parte de las autoridades chinas de un acercamiento a Estados Unidos, a pesar de las reticencias que su ideología comunista y su nacionalismo anti-imperialista les hacía albergar hacia Washington.

\section{Acercamiento a Washington}

Por primera vez la política exterior de la República Popular China va a estar marcada fundamentalmente por consideraciones de carácter pragmático en vez de por planteamientos ideológicos como la solidaridad ente movimientos comunistas y un nacionalismo fuertemente anti-imperialista. En un momento en que Nixon estaba dispuesto a explorar la posibilidad de mejorar sustancialmente las relaciones con Pekín (Ross 1995), Mao, Zhou Enlai y la cúpula del Ejército Popular de Liberación entendían que la mejor forma de enfrentar la amenaza soviética era aproximarse a la otra gran superpotencia. Esta coincidencia fue la que permitió un realineamiento de los vértices del triángulo estratégico conformado por Estados Unidos, la Unión Soviética y China.

Aunque el principal objetivo que perseguían las autoridades chinas con este giro político era reducir las posibilidades de una eventual agresión soviética, eran conscientes de que éste no era el único rédito que podía propiciarles esta maniobra (Jia 2002, Scalapino 1974). La distensión con Washington facilitó la entrada de la República Popular China en Naciones Unidas (1971), la aceptación por parte de Nixon, en Shangái (1972), del principio de una sola 
China, y el reconocimiento de un creciente número de países a Pekín como el único gobierno legítimo de toda China. Todo ello redundaba en un creciente aislamiento diplomático de la República de China, que teóricamente mejoraba las perspectivas de reunificación de las dos orillas del estrecho en los términos marcados por Pekín. Además, también se propiciaba un estrechamiento de los vínculos con Japón, que era un importante socio comercial de China.

En otras palabras, el inicio de la integración de china en la comunidad internacional en base a una política exterior esencialmente pragmática, no lo marcó el periodo reformista, sino que se produce a finales del maoísmo. Deng Xiaoping profundizará más adelante en este proceso de acercamiento al bloque capitalista con la firma del Tratado de Paz y Amistad China Japón (1978) y el establecimiento de relaciones diplomáticas oficiales con Estados Unidos (1979).

\section{La política de puertas abiertas}

Deng Xiaoping continuó aplicando una política exterior pragmática, no sólo ya por motivos de seguridad nacional, también como complemento imprescindible para impulsar el nuevo modelo de desarrollo que quería implementar en China. La internacionalización fue, junto a la liberalización, uno de los dos pilares sobre los que se sustentaron las reformas económicas de Deng Xiaoping. Deng era consciente de la creciente prosperidad de la que disfrutaban los chinos que vivían fuera de la República Popular China, en Taiwán, en Hong Kong, en Singapur... y entendió que esto sólo sería posible en China atrayendo inversión, tecnología, y conocimiento de otros países. Todo ello orientado a convertir a China en la nueva fábrica del mundo, lo que también requería, obviamente, la llegada de los productos chinos a los mercados internacionales (Yeh 1993). De ahí su empeño en mejorar todavía más las relaciones con Estados Unidos, Japón y Europa.

Paralelamente, debido a los cambios impulsados por Mijail Gorbachov dentro de la Unión Soviética y al deshielo de las relaciones entre las dos superpotencias, desde mediados de los años ochenta los líderes chinos comenzaron a ver mucho menos probable verse envueltos en un conflicto bélico con Moscú. Esto hizo que en su paradigma de seguridad comenzase a cobrar preeminencia la dimensión económica frente a la militar, y que impulsasen un acercamiento a la Unión Soviética, que culminó con la vista de Gorbachov a Pekín en 1989. De esta manera, China adoptaba una política exterior global, sin decantarse por ninguno de los dos bloques, subrayando, como ya hiciese Zhou Enlai en 1955 en Bandung, su carácter pacífico e independiente. 


\section{Mantener un perfil bajo}

Tras la supresión del movimiento de Tiananmen en 1989 y la caída de la inmensa mayoría de regímenes comunistas, el liderazgo del Partido Comunista Chino quedó en una situación muy precaria (Yahuda 1992). El final de la Guerra Fría, con la victoria del bloque capitalista, va a cambiar radicalmente el lugar de China en la escena internacional. A ojos de los países occidentales, el régimen de Pekín ya no será la rama amable del comunismo, con la que era conveniente congeniar para debilitar al bloque soviético, sino el último gran estado comunista del planeta. En esa coyuntura los países occidentales impusieron sanciones y un aislamiento diplomático a China ${ }^{6}$.

Para numerosos expertos internacionales, el final de la República Popular China era inminente. El fusilamiento de Ceaucescu en la Navidad de 1989 incrementó el sentimiento de inseguridad de los líderes chinos, que temían acabar sus días como el dictador rumano. En ese contexto, Deng Xiaoping fraguó "la estrategia de los 24 caracteres": "Observar con calma; asegurar nuestra posición; afrontar los hechos con tranquilidad; esconder nuestras capacidades y ganar tiempo; mantener un perfil bajo; y nunca reclamar liderazgo" (Garver 1993). Es decir, a inicios de los años 90 los cálculos en materia de seguridad volvieron a ser el factor más determinante en la confección de la política exterior china.

La paradoja era que Estados Unidos y sus socios no sólo eran vistos por Deng como la principal amenaza para la continuidad del régimen, sino también como socios esenciales para su mantenimiento, pues jugaban un papel fundamental en el modelo de desarrollo económico que podía brindar a China un crecimiento rápido y sostenido. De ahí que esta nueva política exterior tuviese como uno de sus principales objetivos la mejora de las relaciones económicas de Pekín con los países capitalistas (Chen 1993). Al mismo tiempo, también debía profundizarse en las relaciones con otros países para evitar verse aislado internacionalmente si los países occidentales volvían a intensificar la presión sobre el régimen de Pekín. Es más, todo ello debía hacerse sin antagonizar a Estados Unidos y sus socios, so pena de que intentasen favorecer un cambio de régimen político en China.

Una década después, el mantenimiento del Partido Comunista Chino en el poder, sin haber tenido que volver a afrontar protestas tan masivas como las de Tiananmen, unido a acontecimientos internacionales con un fuerte componente simbólico, como la elección de Pekín para celebrar las Olimpiadas de 2008 o la entrada de China en la Organización Mundial del Comercio, evidenciaban el éxito de esta estrategia.

\footnotetext{
${ }^{6}$ En aquel contexto de presión internacional sobre el régimen de Pekín, la diplomacia española fue pionera dentro de la Comunidad Económica Europea a la hora de explorar un mayor acercamiento diplomático a China (Bregolat 2007).
} 
A inicios del siglo XXI las tornas se habían girado hasta el punto de que se comenzaba a hablar del siglo de China (Fishman 2004, Shenkar 2004). Ya no era China quien se sentía amenazada, sino que eran otros quienes percibían su pujanza como una amenaza. Al mismo tiempo que multiplicaba su producto interior bruto, Pekín también aumentaba su presupuesto militar, que pasó de 8.000 a 24.000 millones de dólares entre 1992 y 2003. Paralelamente, China desembarcaba o incrementaba exponencialmente su presencia en zonas como África y América Latina, que estaban fuera de sus áreas tradicionales de influencia.

Para paliar estas inquietudes, la diplomacia pública china comenzó a enfatizar el carácter pacífico de su proceso de inserción internacional, apelando primero a la teoría del "ascenso pacífico", reformulada más tarde como "desarrollo pacífico", por considerarse una expresión más tranquilizadora (Hu 2005, Zheng 2005). Desde Pekín se repetía como un mantra que, siendo China un país en vías de desarrollo, no podía desempeñar un papel protagónico dentro de la comunidad internacional, pues debía priorizar sus asuntos internos. Todavía más remoto se presentaba un eventual cuestionamiento del orden internacional vigente por parte de Pekín, dado que éste había sido clave para favorecer su fulgurante desarrollo. Se argumentaba que, siendo el comercio y la inversión extranjera esenciales para el progreso de China, el gigante asiático estaba especialmente interesado en mantener un entorno internacional estable y pacífico, de ahí que recurriese esencialmente a la diplomacia a la hora de defender sus intereses en el exterior.

Nótese que esta política exterior basada en mantener un perfil internacional bajo ha sido la más duradera de la historia de la República Popular China, con más de un cuarto de siglo de vigencia. Durante este periodo no sólo el gobierno central chino, sino también múltiples actores como gobiernos locales, empresas, fundaciones, centros de investigación, universidades, etc., han profundizado de manera muy pronunciada en su inserción internacional. Esto hace que la acción exterior china sea cada vez más compleja y tenga más matices, que pueden llevar a líneas de acción contradictorias (Johnston y Ross 2006).

Un ejemplo especialmente relevante, por el creciente impacto que está teniendo en la política exterior china, es la recuperación del nacionalismo como fuente de legitimación del Partido Comunista Chino desde inicios de los años 90. Esta maniobra, que ha contribuido a consolidar al régimen de Pekín, también ha tenido efectos colaterales como conferir a la población china una mayor influencia sobre la política exterior de su país y favorecer tensiones con algunos de sus socios clave, especialmente Japón y Estados Unidos (Esteban 2007). 


\section{Una política exterior más asertiva}

La Gran Recesión iniciada con el estallido de la burbuja inmobiliaria en Estados Unidos, conllevó una serie de cambios en el panorama internacional extraordinariamente relevantes para la estrategia de acción exterior de China. En primer lugar, comenzaba a extenderse entre los líderes, los funcionarios y los académicos chinos la visión de que el equilibrio de poder internacional se estaba decantando hacia el Este, en detrimento de Occidente, debido especialmente al declive relativo sufrido por Estados Unidos. A sus ojos se estaba acelerando la transición de un mundo unipolar a otro multipolar en el que China debía jugar un papel más activo (Shambaugh 2011).

En esta coyuntura Pekín consideraba que había llegado el momento de que China y otros países emergentes asumiesen un mayor protagonismo en la gobernanza global. Esto se materializó en la primera cumbre de los BRIC, celebrada en 2009, y en el desplazamiento del G-8 por el G-20 como principal foro sobre la gobernanza de la economía internacional. En cualquier caso, China no lideró abiertamente ninguna de estas iniciativas, tarea que recayó en Moscú y Washington respectivamente.

Otra novedad de este periodo fue la retórica sobre la necesidad de proteger a los ciudadanos y los activos chinos en el extranjero, que potencialmente podría entrar en contradicción con el principio de no intervención, uno de los pilares tradicionales de la política exterior de la República Popular China (Liu 2012). Las dos manifestaciones más evidentes de esta nueva línea de actuación fueron la operación para repatriar en la primavera de 2011 a unos 35.000 ciudadanos chinos residentes en Libia y la reacción a la masacre de 13 marineros chinos en el río Mekong en la frontera entre Myanmar y Tailandia, que aumentó la influencia china en la zona y acabó con la ejecución en China del responsable de la matanza.

La llegada al poder de Xi Jinping, que alcanzó la secretaría general del Partido Comunista Chino en noviembre de 2012 y la presidencia de la República Popular China en marzo de 2013, profundizó en el distanciamiento de la estrategia de perfil bajo establecida por Deng Xiaoping (Noesselt 2015). Apenas unos días después de asumir la jefatura del partido, durante una visita al Museo Nacional de China, Xi Jinping presentó su teoría del Sueño Chino, que pretende ser su mayor contribución teórica al pensamiento socialista. A través de este concepto, Xi plasma su visión sobre cuáles son las prioridades de la población china, confiriendo un lugar preeminente a la "revitalización de la nación" y al "reforzamiento del ejército", además de a la "prosperidad" y la "mejora de la calidad de vida de las personas". Las implicaciones del pensamiento de $\mathrm{Xi}$ sobre la política exterior china se entienden mejor si analizamos el Informe del 18 Congreso Nacional del Partido Comunista Chino y su libro "La gobernación y administración de China" (Xi 2014). Aquí 
encontramos múltiples referencias a la necesidad de que China asuma un papel más activo dentro de la comunidad internacional, lo que da lugar a diferentes derivadas con un impacto ambivalente sobre otros países, que pueden encontrar nuevas oportunidades de cooperación o un mayor riesgo de conflicto en este proceso.

Por un lado, estos textos recogen la visión del institucionalismo neoliberal que ha sido una constante de la política exterior china posterior a la Guerra Fría. Se enfatiza que vivimos en un mundo globalizado e interdependiente donde el alto potencial para establecer relaciones de cooperación mutuamente beneficiosas hace que resulte obsoleto concebir las relaciones internacionales como un juego de suma cero. En este sentido, se subraya la teoría del desarrollo pacífico y que ningún país puede hacer frente por sí solo a los retos que debe encarar, de ahí que resulte imprescindible la cooperación entre los diferentes estados. En este proceso, China se presenta como un actor dispuesto a asumir mayores responsabilidades a la hora de promover y articular dicha cooperación. Por otro lado, se han multiplicado las referencias a los "intereses nacionales de China". Estos "intereses centrales" son los que alentarían o limitarían la cooperación de Pekín con otros estados. Este énfasis en los intereses propios de China se está traduciendo en una política exterior más asertiva, especialmente en relación a las disputas territoriales que mantiene con sus vecinos en los mares de China Meridional y de China Oriental.

En relación con esa vertiente más cooperativa, los líderes chinos son cada vez más conscientes de la importancia de que su país goce de buena imagen en el exterior, de ahí que hayan redoblado los esfuerzos diplomáticos y propagandísticos para transmitir la idea de que China no es una amenaza. Los argumentos son ya conocidos, el compromiso con la diplomacia como vía para resolver los conflictos, con la liberalización del comercio internacional, y con el respeto por los modelos de organización sociopolíticos de otros países. Más novedosa que esta retórica son algunas de las acciones concretas que está adoptando Pekín.

En el pasado reciente, a China se le ha reprochado reiteradamente estar beneficiándose para su desarrollo del orden internacional vigente sin estar dispuesta a asumir la responsabilidad que debería corresponderle sobre el mantenimiento del mismo en función de sus capacidades. Sin embargo, resulta evidente que con Xi Jinping Pekín ha intensificado su compromiso para actuar como un actor responsable dentro de la comunidad internacional, que promueve bienes públicos globales, como la mejora del medio ambiente o el mantenimiento de la paz. A mediados de noviembre de 2014 China y Estados Unidos anunciaron un acuerdo conjunto para luchar contra el cambio climático. Pekín se comprometía por primera vez a reducir el volumen total de sus emisiones, como tarde en 2030, y a aumentar hasta el 20\% la proporción 
de fuentes no contaminantes de energía, que ahora no alcanzan el 10\% de su consumo total de energía. China creó así un precedente para otros países en vías de desarrollo que hasta el momento se habían mostrado reacios a reducir sus emisiones (Daugirdas y Morterson 2015).

Asimismo, en un conflicto tan complejo como el de Afganistán, Pekín ha modificado de forma constructiva su postura en el último año. Después de más de una década rechazando desempeñar un papel político activo en esta cuestión, el gobierno chino está intentando mediar en un proceso de paz, que tendría el apoyo de Estados Unidos y Pakistán, y estaría protagonizado por el gobierno afgano y los talibanes afganos (Scobell 2015). Esta posibilidad fue explorada en la visita que el presidente Asharf Ghani Ahmadzai realizó a China en octubre de 2014, en la que fuera su primera salida de trabajo al extranjero, y por las dos delegaciones enviadas por los talibanes afganos a Pekín en la segunda mitad de 2014. Estos primeros contactos resultaron positivos y en mayo de 2015 se celebró en Urumqi un encuentro entre Mohammed Masoom Stanekzailas, actual ministro de defensa en funciones de Afganistán, y ex altos cargos del gobierno talibán. Esto cristalizó en una primera ronda de negociaciones, celebrada a principios de julio de 2015 en Islamabad, a la que debía haber seguido una segunda ronda en China. Además, Pekín está entrenando a policías afganos y ha prometido ayuda por valor de 327 millones de dólares al gobierno de Kabul. Otro conflicto en el que China también está mediando es del de Kachin, que enfrenta al gobierno birmano con el ejército independiente de Kachin.

Además, China se está esforzando, especialmente en su vecindad por mostrarse como un país que ofrece oportunidades de desarrollo a otros estados (Zhao y Xin 2015) ${ }^{7}$. Por un lado, la diplomacia pública china difunde numerosa información sobre el papel del comercio y las inversiones internacionales de China, no en balde el gigante asiático es el principal mercado para las exportaciones de 32 países. Por otro, Pekín está liderando iniciativas concretas como el Banco Asiático de Inversión en Infraestructuras o la nueva ruta de la seda, conocida oficialmente como "una franja, una ruta" (Esteban y Otero 2015). Con estas iniciativas, las autoridades chinas pretenden, entre otras cosas, demostrar que contribuyen activamente al desarrollo económico de otros países abordando uno de los mayores obstáculos que enfrenta Asia para ser más prospera: la falta de infraestructuras. Las necesidades de financiación de infraestructuras es de tal magnitud, unos 750.000 millones de dólares anuales según el Banco Asiático de Desarrollo que, incluso desde esta institución, cuyos préstamos anuales ascienden a unos 14.000 millones de dólares, se ha valorado positivamente la creación del Banco Asiático de Inversión en Infraestructura,

7 En otras regiones, como América Latina, diferentes organismos multilaterales comparten la visión de que China puede ser un valioso aliado a la hora de contribuir al desarrollo local (OCDE, CEPAL, CAF 2015). 
con el que han llegado a acuerdos para explorar la cofinanciación de proyectos. La expectación sobre este nuevo banco de desarrollo, con sede en Pekín, es tal que, a pesar de la oposición de Estados Unidos, más de 50 países se han unido a él como miembros fundadores. Entre ellos están algunos socios tradicionales de Washington como el Reino Unido, Australia y Corea del Sur.

Por el contrario, hay otros vectores del abandono por parte de China de su anterior política exterior de perfil bajo que están generando preocupación fuera de sus fronteras. Especialmente alarmante es la mayor propensión de Pekín a actuar unilateralmente para modificar el status quo en varias de las disputas territoriales y marítimas que le enfrentan con algunos de sus vecinos. A medida que China incrementa su poderío militar parece más proclive a hacer uso de estas capacidades para hacer valer su postura en disputas sobre las que existe gran controversia dentro de la comunidad internacional, sin tener en cuenta las posiciones de otros.

Los dos ejemplos más evidentes se están dando en los mares de China Meridional y de China Oriental (Dreyer 2015). En ambas zonas ha crecido sensiblemente en los tres últimos años el número de incursiones de aviones y embarcaciones chinos en áreas en disputa. Asimismo, China estableció en noviembre de 2013 una zona de identificación aérea en el mar de China Oriental y se está planteando hacer lo propio sobre las islas artificiales que está construyendo en aguas en disputa en el Mar del Sur de China.

La zona de identificación aérea establecida por China se extiende en parte sobre territorios como las islas Senkaku, también conocidas como Diaoyu en China o Daioyutai en Taiwán, cuya soberanía se disputan Japón, la República Popular China y la República de China. Lo que resulta particularmente desestabilizador es que esta zona de identificación china se superpone parcialmente a otras establecidas previamente por Japón, Corea del Sur, y Taiwán; y que se exija a las aeronaves que atraviesan dicha zona informar a las autoridades chinas pertinentes, aunque no vayan a atravesar espacio aéreo soberano chino (Hornung 2015). En el Mar del Sur de China estamos asistiendo a una tónica similar (Chan y Li 2015). En 2013 Pekín publicó un mapa oficial que añadía un marcador más a la parte de este mar que reclama. En 2014 la China National Petroleum Corporation envío una plataforma petrolífera a aguas disputadas con Vietnam, cerca de las islas Paracelso, donde estuvo realizando prospecciones durante más de dos meses. Desde 2015 está construyendo islas artificiales en las islas Spratly, lo que contradice la declaración de conducta en el Mar de China Meridional firmada por China y los países de la Asociación de Naciones del Sudeste Asiático en 2002. 


\section{8. ¿Qué podemos esperar en el futuro?}

Las crecientes capacidades de China unidas a la disposición de sus líderes a adoptar un mayor protagonismo dentro de la comunidad internacional hacen que la influencia de Pekín se deje sentir cada vez con más fuerza a lo largo y ancho del planeta. Este impacto es ambivalente, pues la política exterior china combina una mayor colaboración en múltiples ámbitos con actores de otros países con una mayor asertividad a la hora de defender sus intereses nacionales, especialmente en relación a varias de las disputas territoriales que mantiene con países vecinos.

Estas contradicciones en la política exterior china son fruto de las discordancias existentes entre las dos mayores fuentes de legitimidad del régimen de Pekín. A finales de los 70 Deng Xiaoping sustituyó el ideario revolucionario, que había perdido predicamento incluso entre la cúpula del partido, por el desarrollo económico como la principal justificación del monopolio del Partido Comunista Chino sobre el poder político. Tras la supresión del Movimiento de Tiananmen y en plena crisis del comunismo internacional, este énfasis desarrollista se vio complementado con una intensa campaña de adoctrinamiento nacionalista.

Desde inicios de los años 90 los líderes chinos han cultivado ambas fuentes de legitimidad para reforzar su popularidad. El problema es que haciendo esto fomentan dos lógicas de actuación que pueden resultar contradictorias. Por un lado, el desarrollo económico de China sigue estando muy supeditado al mantenimiento de un orden internacional pacífico y de buenas relaciones con otros estados. Por otro lado, el creciente nacionalismo de la sociedad y los dirigentes chinos hace que cada vez sean más numerosas las voces que demandan una actitud firme en las crisis internacionales que sacuden periódicamente las relaciones de China con el exterior, especialmente con aquellos países con los que mantiene contenciosos territoriales.

Por el momento, la China responsable se sigue imponiendo en términos generales a la China beligerante. Evitar que un nacionalismo confrontacional secuestre la política exterior china será fundamental para mantener la paz en Asia Oriental. Esto dependerá en gran parte de la propia evolución interna de China y en escenarios especialmente sensibles como el estrecho de Taiwán y los mares de China Meridional y de China Oriental. Esperemos que ambas situaciones se conjuguen para que ni gobierne China un líder que sustente fundamentalmente su autoridad en sus credenciales nacionalistas, ni Pekín tenga que hacer frente a modificaciones unilaterales del status quo en estos conflictos impulsadas por otros actores. 


\section{Referencias bibliográficas:}

Bregolat, Eugenio (2007). La segunda revolución china. Barcelona: Destino. Chan, Irene y Li Mingjian (2015). "New Chinese Leadership, New Policy in the South China Sea Dispute?", Journal of Chinese Political Science 20 (1), pp. 35-50.

Chen, Jian (2001). Mao's China and the Cold War. Chapel Hill: University of North Carolina Press.

Chen, Jian (1994). China's Road to the Korean War. The Making of the SinoAmerican Confrontation. Nueva York: Columbia University Press.

Chen, Qimao (1993). "New Approaches in China's Foreign Policy: The PostCold War Era", Asian Survey 33 (3), pp. 237-251.

Christensen, Thomas J. (1996). Useful Adversaries: Grand Strategy, Domestic Mobilization, and Sino-American Conflict, 1947-1958. Princeton: Princeton University Press.

Daugirdas, Kristina y Julian D. Mortenson (2015). "United States and China

Make Joint Announcement to Reduce Greenhouse Gas Emissions, Bolstering Multilateral Climate Change Negotiations, American Journal of International Law, 109 (1), pp. 195-200.

Dreyer, June T. (2015). "The Rise of China and the Geopolitics of East Asia", Orbis 59 (4), pp. 518-529.

Esteban, Mario (2007). China después de Tiananmen. Nacionalismo y cambio político. Barcelona: Ediciones Bellatera.

Esteban, Mario y Miguel Otero (2015). “¿Qué podemos esperar de la nueva Ruta de la Seda y del Banco Asiático de Inversión en Infraestructuras liderados por China?", Análisis Real Instituto Elcano 19.

Fishman, Ted C. (2004). "The Chinese Century", The New York Times, $14 / 07 / 2004$.

Garver, John W. (1993). "The Chinese Communist Party and the Collapse of Soviet Communism", China Quarterly 133, pp. 1-26.

Gittings, John (1969). "The Great-Power Triangle and Chinese Foreign Policy", China Quarterly 39, pp. 41-54.

Hornung, Jeffrey (2015). Japan's Pushback of China, The Washington Quarterly 38 (1), pp. 167-183.

Hu, Jintao (2005). "Build Towards a Harmonious World of Lasting Peace and Common Prosperity". Discurso del Presidente de la República Popular China, Hu Jintao, ante la Asamblea General de Naciones Unidas. Disponible es: http://www.un.org/webcast/summit2005/statements15/ china050915eng.pdf.

Hunt, Michael H. (1996). The Genesis of Chinese Communist Foreign Policy. Nueva York: Columbia University Press. 
Jia, Qingguo (2002), "Chinese Relations with the United States", en The Golden Age of the US-China-Japan Triangle (1972-1989). Cambridge: Harvard University Press, pp. 109-132.

Johnson, Chalmers A. (1962). Peasant Nationalism and Communist Power: The Emergence of Revolutionary China 1937-1945. Stanford: University Press Stanford.

Johnston, Alastair I. y Robert S. Ross (2006). New Directions in the Study of China's Foreign Policy. Stanford: University Press Stanford.

Khrushchev, Nikita (1970). Khrushchev Remembers. Boston: Little Browm.

Li, Mingjian (2012). Mao's China and the Sino-Soviet split: ideological dilemma. Londres: Routledge.

Liu, Tewa (2012). "China and Responsibility to Protect: Maintenance and Change of Its Policy for Intervention”, The Pacific Review 25 (1), pp. 153-173.

Lüthi, Lorenz M. (2008). The Sino-Soviet Split: Cold War in the Communist World. Princeton: Princeton University Press.

Lüthi, Lorenz M. (2010). "Sino-Soviet Relations during the Mao Years, 19491969", en China Learns from the Soviet Union, 1949-present. Lanham: Lexington Books, pp. 27-59.

Mao, Zedong (1949a). "Informe ante la II sesion plenaria del Comite Central elegido en el VII Congreso Nacional del Partido Comunista de China”, en Obras escogidas de Mao Tse-tung Tomo IV (1976). Pekín: Ediciones en Lenguas Extranjeras, pp. 375-390.

Mao, Zedong (1949b). "Sobre la dictadura democratica popular", en Obras escogidas de Mao Tse-tung tomo IV (1976). Pekín: Ediciones en Lenguas Extranjeras, pp. 425-439.

Mao, Zedong (1959). "Outline for a Speech on the International Situation". Disponible en: http://digitalarchive.wilsoncenter.org/document/118893.

Noesselt, Nele (2015). "China's Foreign Strategy After the $18^{\text {th }}$ Party Congress: Business as Usual”, Journal of Chinese Political Science 20, pp. 17-33.

Niu Jun (1998). "The Origins of the Sino-Soviet Alliance", en Brothers in Arms: The Rise and Fall of the Sino-Soviet Alliance, 1945-1963. Stanford: Stanford University Press, pp. 47-89.

OCDE, CEPAL, CAF (2015). Perspectivas económicas de América Latina 2016: Hacia una nueva integración con China. Paris: OCDE Publishing.

Robinson, Thomas W. (1972). "The Sino-Soviet Border Dispute: Background Development, and the March 1969 Clashes", The American Political Science Review 64 (4), pp. 1175-1202.

Ross, Robert S. (1995). Negotiating Cooperation: The United States and China, 1969-1989. Stanford: Stanford University Press. 
Scobell, Andrew (2015). "China Ponders Post-2014 Afghanistan", Asian Survey, 55 (2), pp. 325-345.

Shambaugh, David (2011). "Coping with a conflicted China", The Washington Quarterly 34 (1), pp. 7-27.

Scalapino, Robert A. (1974). "China and the balance of power", Foreign Affairs 52, pp. 349-385.

Scott, David (2008). China and the International System, 1840-1949, Power, Presence, and Perceptions in a Century of Humilliation. Nueva York: State University of New York Press.

Schram, Stuart R. (1973). Authority Participation and Cultural Change in China. Cambridge: Cambridge University Press.

Shenkar, Oded (2004). The Chinese Century. The Rising Chinese Economy and Its Impact on the Global Economy, the Balance of Power, and Your Job. Upper Saddle River: Prenctice Hall.

Teiwes, Frederick C. (1997). "The Establishment and Consolidation of the New Regime (1949-57)", en The Eras of Mao and Deng. Cambridge: Cambridge University Press, pp. 5-86.

Westad, Odd A. (ed.) (1998). Brothers in Arms: The Rise and Fall of the SinoSoviet Alliance, 1945-1963. Stanford: Stanford University Press.

Xi, Jinping (2014). La gobernación y administración de China. Pekín: Ediciones en Lenguas Extranjeras.

Yahuda, Michael B. (1992). "Chinese Foreign Policy and the Collapse of Communism”, SAIS Review, 12 (1), pp. 125-137.

Yeh, Kungchia (1993). "Foreign Trade, Capital Inflow, and Technology Transfer under the Open-Door Policy", en China in the Era of Deng Xiaoping: A Decade of Reform. Nueva York: M.E. Sharpe, pp. 124-147.

Zhang, Baijia. (2011). "Objectives and Choices: 60 Years of Chinese Diplomacy”, Qiushi 3 (4). Disponible es: http://english.qstheory.cn/ selections/201112/t20111229_132740.htm.

Zhao, Kejin y Xin Gao (2015). "Pursuing the Chinese Dream: Institutional Changes of Chinese Diplomacy under President Xi Jinping", China Quarterly of International Strategic Studies 1 (1), pp. 35-57.

Zheng, Bijian (2005). "China's" Peaceful Rise" to Great-Power Status", Foreign Affairs 84 (5), pp. 18-24. 